\title{
From Communications Game to Cities Tango
}

\author{
Ernest Edmonds* \\ IOCT, LMS, \\ De Montfort University, \\ The Gateway, Leicester LE1 9BH, UK \\ and \\ C\&CS, School of Software, \\ FEIT, UTS, \\ P.O. Box 123 Broadway, Sydney, NSW 2007, Australia \\ E-mail: ernest@ernestedmonds.com \\ *Corresponding author
}

\section{Francesca Franco}

IOCT, LMS,

De Montfort University,

The Gateway, Leicester LE1 9BH, UK

E-mail: ffranco@dmu.ac.uk

\begin{abstract}
The paper first discusses early work that predated internet art and that was concerned with active audience participation in electronic art and describes the path of development of the first author's artworks that have looked at human to human communication through electronic (computer) systems from 1970 until today. The fundamental concept has been to make artworks that explore human communication through conversations using restricted languages. The initial inspiration was a set of studies of early infant language development. The paper goes on to describe the latest developments in this series of artworks: Cities Tango.
\end{abstract}

Keywords: generative art; digital art; interactivity; audience participation; Communications Game; Shaping Form; art and technology.

Reference to this paper should be made as follows: Edmonds, E. and Franco, F. (2013) 'From Communications Game to Cities Tango', Int. J. Creative Computing, Vol. 1, No. 1, pp.120-132.

Biographical notes: Ernest Edmonds is a pioneering Digital Artist and international expert on creative human-computer interaction, currently working both in the UK and Australia. He has exhibited computer-based art around the world since 1970 . He has published extensively and been an invited speaker at many international events. His recent books include On New Constructs in Art, Artists Bookworks, UK, 2005 and (edited with Linda Candy) Interacting: Art, Research and the Creative Practitioner, Libri Press, UK, 2011. He co-founded the ACM Creativity and Cognition conference series. He is the Editor-in-Chief of Transactions, the fast track section of the leading MIT Press journal Leonardo. 
Francesca Franco is Research Fellow at the Institute of Creative Technologies, De Montfort University, Leicester, where she is studying the Ernest Edmonds Archive of computational art material held at the Victoria \& Albert Museum. Her most recent publications include 'The first computer art show at the 1970 Venice Biennale. An experiment or product of the bourgeois culture?' in Relive: Media Art Histories, Cubitt and Thomas, editors, MIT Press (2013);

'Exploring intersections: Ernest Edmonds and his time-based generative art', Digital Creativity, Vol. 24, No. 3 (2013); and 'Documenting art as art: the case of notes (2000-ongoing) by British artist Ernest Edmonds', Visual Resources: An International Journal of Documentation, Vol. 29, No. 4 (2013).

\section{Introduction}

Today, it is sometimes hard to imagine the world before the internet and the World Wide Web. This is as true in art as in the everyday use of modern phones. The paper is concerned with art experiments in conceptual social computing prior to the invention of that notion. A concern in art for human communication, for the underlying concepts of conversation is not confined to the digital world, but the developments in that area in recent decades has enabled significant developments.

In the introduction to the 1983 Electra exhibition catalogue, art historian Frank Popper explained how the introduction of new forms of energies in art from 1945 until 1970 created a significant ground for the development of art seen as a social phenomenon. Similarly, the appearance of happenings in the late 1950s and their flourishing in the 1960s stressed the importance of a much closer relationship between the artist and the public. According to Popper, both technology and participative art contributed to make art a more socially oriented phenomenon (Popper, 1968a).

In the mid 1960s, the aesthetic discourse around the viewer's active participation, fostered by various continental European groups, merged with the composite context and ideals of the student movements that had formed internationally around the same time (Popper, 1968b). Kinetic movements such as the French Groupe de Recherche d'Art Visuel (1963), for instance, were interested in defining aspects related to the creative process of art triggered by the spectator's interaction in order to awake people from their apathy and to encourage individual action and people's initiative. Only by actively participating, transforming, and interacting with the artwork the spectator would be the maker of his or her own 'revolution in art' (GRAV, 1963). The result was Labyrinths, a series of experiments of immersive environments created for the 1963 Paris Biennale and exhibited at the Contemporaries Gallery in New York two years later. Labyrinth I was an immersive environment that consisted of several cells where the spectators would find a variety of elements that would be altered and animated by their dynamic participation. One of the cells had walls covered in polished aluminium and the spectator was surrounded by mobile reflecting plates. Mirrors and lights would create 'transformable reflections' that would give to the viewer the impression of being in an instable environment (Popper, 1968b). The seminal work produced by Gustav Metzger from the mid 1960s onwards followed these lines, too.

The notion of the active audience as an integral part of the aesthetic creation developed even further with the introduction of new technologies, including the computer, in art. The UK was at the forefront of such developments. One issue in 
particular, i.e., that of human communication through conversation using restricted languages, was explored from the late 1960s. Some of the old examples presented by Ernest Edmonds in this paper represent some of the pioneering experiments in this field.

Edmonds and Stroud Cornock's DATAPACK represents another seminal example of an early interactive computer-based art system. Created for the Computer Graphics'70 conference held at Brunel University, DATAPACK was, as Cornock described it in 1973, "an example of a matrix that consists of participants, a display, a computer installation and a designated area around the Vickers Building next to the Tate Gallery in London" (Cornock and Edmonds, 1973). DATAPACK was an interactive system that allowed participants to have a 'pseudo-English conversation' with the computer. The results of this conversation were then processed by the machine connected to drum plotter. This was able to identifying a volume space around the Millbank Tower and allocating it to the active participant (Edmonds, 2009a). DATAPACK was written in Fortran, making use of graphics routines. This was almost the standard software environment for making art at that time.

Two works are particularly interesting when analysing the history of computer applications in human to human interaction for art practice. These are George Mallen's Ecogame (Mallen, 2009) and Ernest Edmonds's Communications Game (Edmonds, 1971, 1975).

George Mallen's Ecogame represented the first UK interactive, multimedia, computer-controlled game. It was the result of a collaborative team effort conceived and largely programmed by Mallen for the Computer ' 70 s trade exhibition held at Olympia, London, in September 1970. Ecogame - which was a work grounded in cybernetic theories pioneered mainly by English cybernetician and psychologist Gordon Pask - has been described by Mallen himself as a "computer mediated interactive, multi-media, multi-user game using computer controlled slide projectors to create a visual environment reflecting the decisions players made about allocating resources in a simple model of an economic system" (Swade, 2008). The main notion of the game was to highlight issues arising from the first oil crisis and to encourage participants to consider their behaviour in the system. The game was set up in a small geodesic dome where players sat at terminals and made decisions via light pen interaction. The results of their choices were then fed back to a mini-computer linked to a projector that would show images in the dome, producing an online photographic art show (Mason, 2008).

Communications Game was originally a proposal for the same Computer ' 70 s trade exhibition slot for which Ecogame was selected, but it was not carried out and the detailed design of required input/output devices was not specified. It was proposed that the system of the project be controlled by a digital computer.

The proposal provided stations for a maximum of 15 participants and for a minimum of two participants. The stations are arranged such that a participant can only see one, two, three or four stimulus-providing units within his station and a station is part of the group activity only when it is occupied by a participant. Each unit can be acted upon by the participant in response to a given stimulus. No instructions are given to participants on the manner in which the system of units operates.

A simple example showing how the system could work is as follows: a participant looking at a unit sees the flashing of a stroboscopic light. He may then turn a large dial located above the unit. At first no response is seen, but shortly thereafter the light turns off. He turns the knob to another position but nothing happens. Then he turns the knob 
rapidly between its extreme positions. After doing this for a few seconds, the light comes on again but at a higher frequency ... and so on.

The notion of the interactive audience was fundamental for another British artist working since the late 1950s as an art theorist and practitioner, Stephen Willats. A statement he made in 1968 indicates his main interest in engaging socially with his audience:

\begin{abstract}
"The audience become not just an after-thought, but the prime reason for the provision of triggers...The relationship that the observer has with most of these works is that of a receiver to a transmitter, the problem becoming one of transmitting the necessary conditions for trigger in via the shortest time; the feedback between the audience and the work being a result of this triggering." (Willats, 1968)
\end{abstract}

But it is Roy Ascott who explored the potentials of interconnectivity and found a wider range of meaning. By anticipating the convergence of cybernetics and telematics in the mid 1960s (Ascott, 2003a), Ascott was one of the first artists to experiment the potential of computer networks when they became available in the late 1970s. Amongst the works that exemplify such a discourse are The Pleating of the Text, presented at the exhibition Electra curated by Frank Popper between December 1983 and February 1984 at the Musée d'Art Moderne in Paris; and Planetary Network, shown at the Venice Biennale in 1986.

The Pleating of the Text gave Ascott the opportunity to create a telematic event that combined together his ideas of cybernetics, interactivity and telematics in a way that they would lead to a process of 'dispersed authorship' (Ascott, 2003b). Fairy tale roles were assigned to 11 cities distributed between North America, Europe and Australia. Through remote exchange between artists based in each station, the emerging story was actively unfolded through text and images.

Similarly, Planetary Network was a project for the 1986 Venice Biennale that included a number of telecommunication stations installed at the Arsenal's Corderie within the Technology and Computer Science section. Artists from three continents (USA, Australia, and Europe) created nodes through which information and images were exchanged and modified. Digital images transmitted slowly via phone lines were altered by artists participating to the initiative and by external contributors such as writers, engineers, computer programmers and media activists. Through such projects the term 'artist' has expanded its meaning to 'participant'. In the same way too, the 'artwork' has become the work of several individuals and the notion of artist meaningless.

\title{
2 The communication games
}

Persons in an unfamiliar situation try to 'make sense of it', even though initially it may appear to consist of random factors. Their major problem is to comprehend the situation in question; some would say that the problem is to discover its logic. But Edmonds wished to avoid this notion, as it seemed to imply that there is only one way to understand it, whereas in practice different people often make sense of the same situation in different ways. It can be said that when one has learnt how to deal with people one understands their actions, not always in the strict sense of being able to predict them but simply of not being bewildered by them. 
In no sense are these projects based on a scientific theory of cognition, although participants in one of the projects may be led to question their ideas about cognition. In each project, participants are able to make contact with each other only through very restricted interfaces, i.e., with a very limited set of possible actions and responses. One might say that they try to make sense of the responses that they receive. The responses are such that the participants are likely to understand each other's actions only partially and even that understanding may be transitory. The inspiration for this approach came from studies reported in the late 1960s and early 1970s about the behaviour of very young infants. A newborn baby is interacting with the world around them in a purposeful way from the start: a kind of communication that goes far beyond recognising mother's face is observable in the first week of life (Bower, 1974).

Figure 1 Notes: the layout for Communications Game

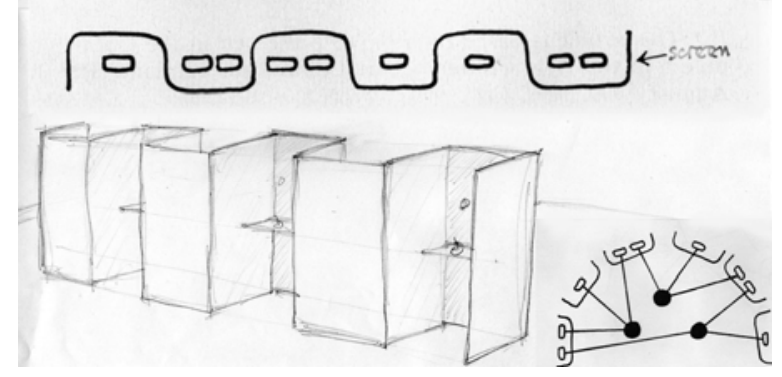

Communications Game was based upon the ideas of the proposed Computer ' 70 s project, but a computer is not used. It was shown in the Invention of Problems II Exhibition at the City of Leicester Polytechnic in 1971 (Cornock, 1971). Only three networks of units are used and each unit is equipped with an input switch for turning on lights in units of the same network and a single light for output. For each participant, the lights provide the stimuli and the switches are the means for the participant to respond.

The work has six stations and there are three networks of three units. Screens or barriers keep participants from seeing the units in another station. Each participant has before him one or two units. The illumination of a light on one of his units is controlled by the other participants by opening or closing their switches in the network. The possible on-off illumination of the lights in any one network is given in Table 1. Further details on this work, including a circuit diagram, are given in Edmonds (1971, 1975). Computer networks were, of-course, only in the most early stages of development around 1970 and so Communications Game was constructed by building hardware from logic circuits designed by Edmonds to implement the concept.

Experience with Communications Game showed that, when there are more than three or four participants and several networks, the multiplicity of signals is beyond the comprehension of the participants. Hence, a simplified version of the game was developed with only one network and three participants, called Communications Game 2. It was installed at the Cognition and Control Exhibition at the Midland Group Gallery in Nottingham in 1972.

Significantly later, a new version of Communications Game was produced that employed a computer-based local area network, Ethernet, but deployed exactly the same concepts. The work was shown in the exhibition Art Creating Society at the Museum of Modern Art Oxford (Edmonds, 1990). 


\section{Tango tangle and shaping form}

An interactive urban screen work and a series of individual interactive pieces provide the background to the newest step arising from the Communication Games. By the time these works were made Fortran was long forgotten. Various environments were used over the years in between, but the interactive works from 2000 on were composed using Max/MSP, an environment that came out of the music research at IRCAM in Paris and had been extended to handle graphics in an extremely flexible way (Manzo, 2011). This environment is, in the digital arts, a commonly used 'extreme programming'. The works are briefly described in this section.

The artwork Tango Tangle was an interactive urban screen piece. It was shown on the large outdoor screen in Federation Square Melbourne in 2006 (Bilda et al., 2007). The display was of a changing set of vertical coloured stripes. The choice of pattern, colours and timing was driven by an analysis of the sounds made into a roaming wireless microphone that was taken around the Square. People could talk or sing and the work responded. At one time a jazz pianist, who was preparing for an evening concert, asked for the microphone to be near the piano and an audio-musical performance was spontaneously given. This work explored interactions with abstract forms (colour stripes) in a public setting. The key point being that the audience consisted of passers by, their for other reasons, such as going to work, and became involved with the art more-or-less by chance.

Figure 2 Tango Tangle in Federation Square (see online version for colours)

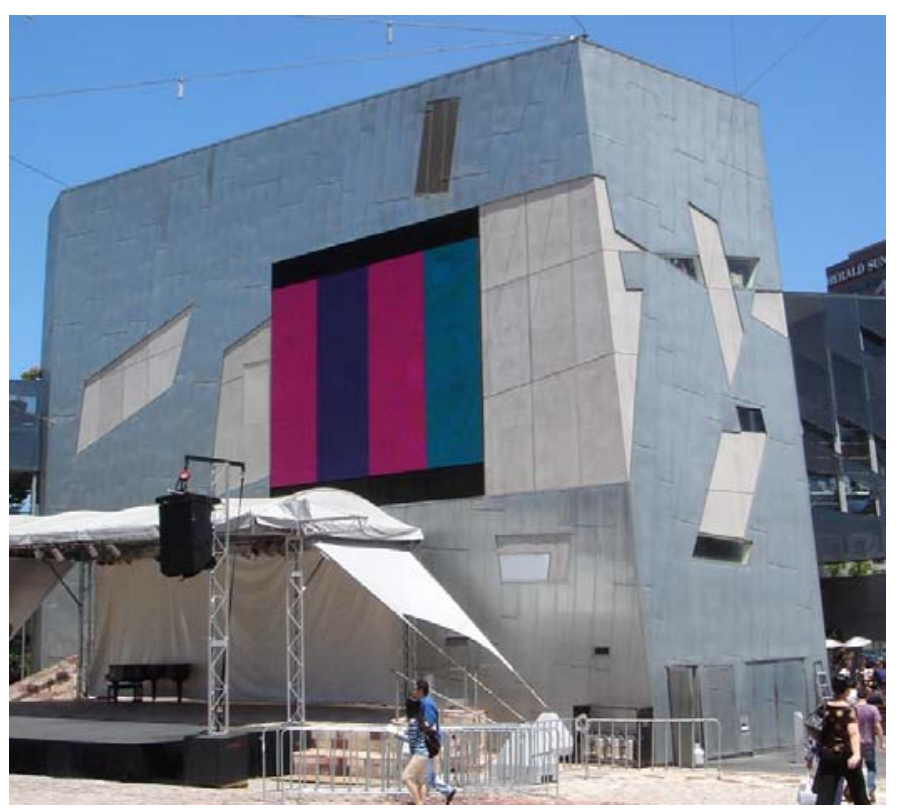

The Shaping Form artworks, on the other hand, are relatively small, in a frame and typically hung on a wall in an art gallery or home. As with Tango Tangle, they mostly consist of changing sets of coloured vertical stripes. However, they are quite different in relation to interaction. Firstly, they use a camera and image analysis to obtain information 
about what is happening in front of them. Secondly, the work accumulates a history of audience activities and that history slowly changes the behaviour of the work, including colour saturation, timing and so on. Shaping Form artworks do not interact (except trivially) in direct and immediate response to what is observed, rather the behaviour develops over time as a result of experience. A month or two on display in a gallery, for example, can lead to clearly observable change.

These Shaping Form pieces are individual stand alone works that were first exhibited in Washington, DC (Jennings, 2007). In Shaping Form, images are generated using rules that determine the colours, the patterns and the timing. These are generative works that are changed by the influence of the environment around them. As mentioned, movement in front of each work is detected and leads to continual changes in the programme that generates the images. People can readily detect the immediate responses of the work to movement but the changes over time are only apparent when there is more prolonged, although not necessarily continuous, contact with it. A first viewing followed by one several months later will reveal noticeable developments in the colours and patterns.

The Communications Games concepts were applied to a development of the Shaping Form works using the World Wide Web. The original Shaping Forms worked from an individual memory. This aspect is significantly changed in the web version. The community made up of the work's distributed audience collectively influence the progress and development of the work.

The web version of Shaping Form uses a collective history. It has a memory that combines all of the experiences that the system has noted through all of the cameras that have been connected to it. Individual experiences are shaped in part by the behaviour of that individual and in part by this collective memory (Edmonds and Amitani, 2008).

The approach adopted extends the notion of interactivity to collective behaviours in the context of web art and so illustrates a creative computational mechanism that embodies an interesting new form of influence, as discussed above. It provides a new form of communication that takes place through the collective memory across the internet.

To return to the communications theme, the Tango Tangle and the Shaping Form works both influenced the latest step in the communication games artwork development. This latest work is known as Cities Tango.

\section{Cities Tango}

The artwork, Cities Tango: between Belfast and Sydney, (Edmonds, 2009b) is a new version of an earlier work that linked Melbourne and Sydney. In all versions, the work is generative, as the Shaping Form ones are. They have a 'life', a behaviour, even when no audience is present.

In the earlier work, screens in Federation Square, Melbourne Australia, and the SAP Facade in Berlin were the two primary components. In each location (which is in very different time zones) the work picks up images from the screen location and reacts to the degree of motion detected. At the same time, the analysed image information is sent over the internet to the other location and forms the second influence on the work's behaviour.

The Melbourne/Berlin version was used to learn about the nature of the interactions that might take place and to inform the design of the main work shown to date, that is the Belfast/Sydney version. In this case, one node was within the exhibition held as part of 
the ISEA event in the concourse area of the Waterside Building, Belfast. The other node was in the window of the Conny Dietzschold Gallery Sydney, a commercial art gallery specialising in contemporary and concrete art. The installation was timed to coincide both with the major ISEA event and with a gallery opening in Sydney.

Figure 3 Cities Tango in Sydney A (see online version for colours)

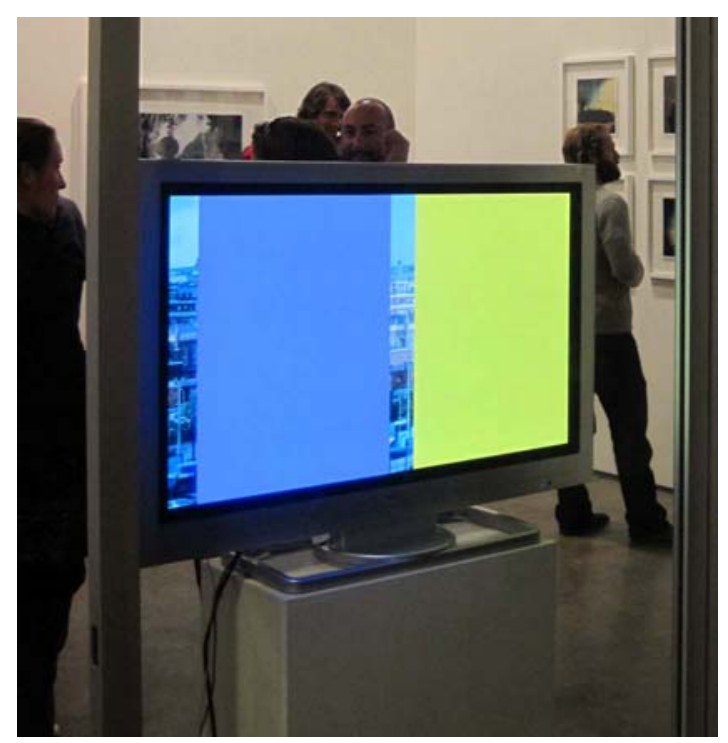

Figure 4 Cities Tango in Sydney B (see online version for colours)

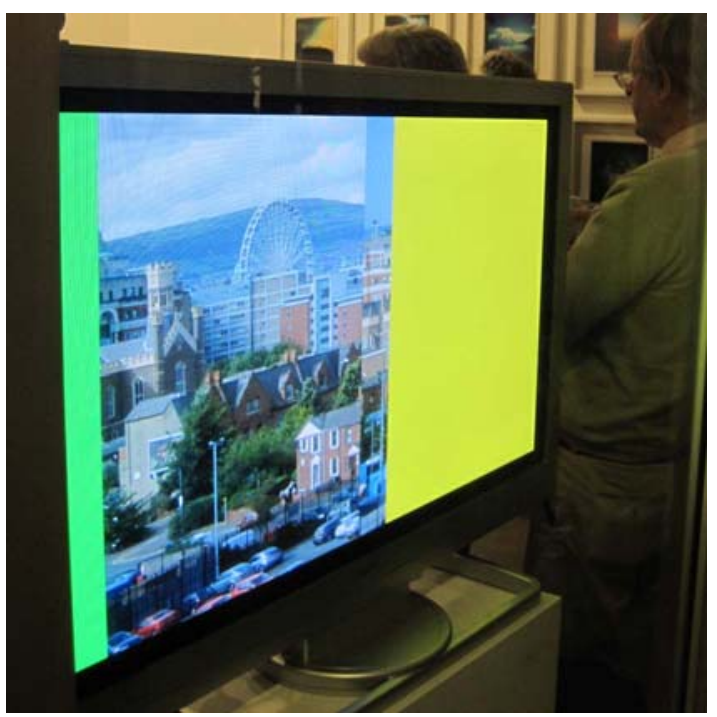


Figure 5 Cities Tango in Sydney C (see online version for colours)

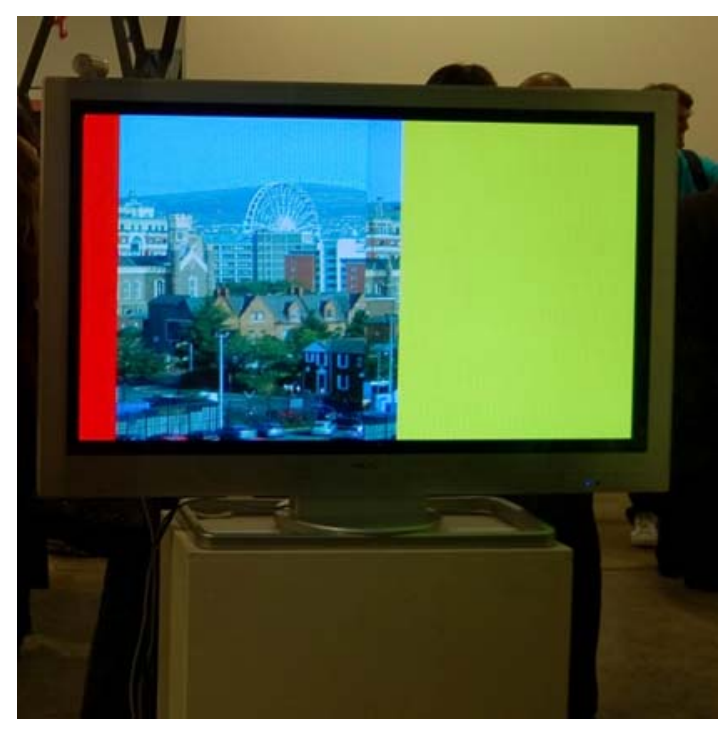

Figure 6 Cities Tango in Belfast A (see online version for colours)

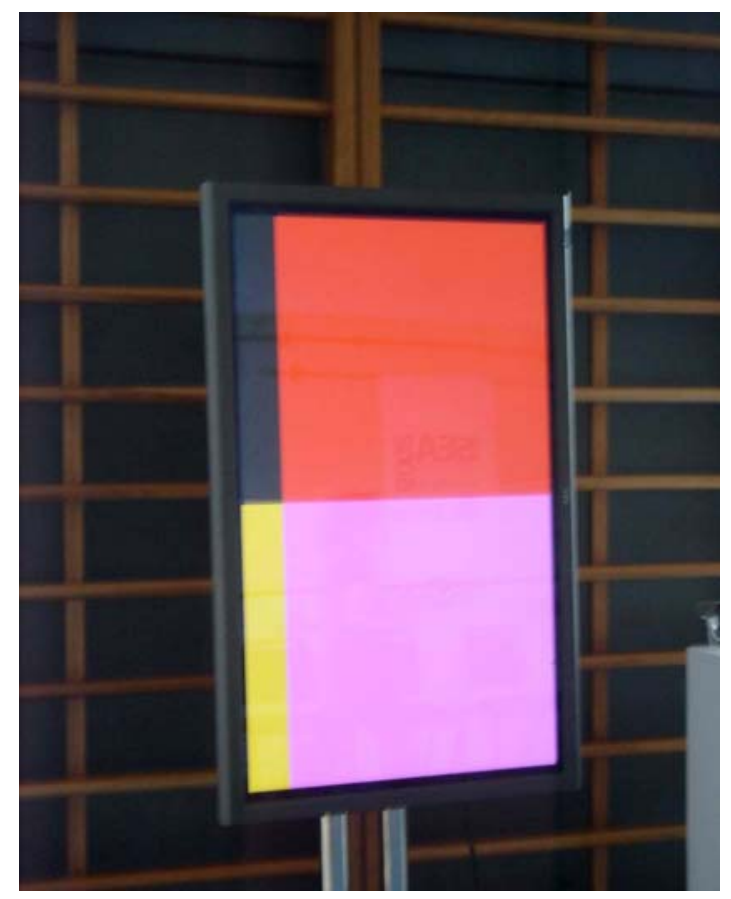


From Communications Game to Cities Tango

Figure 7 Cities Tango in Belfast B (see online version for colours)

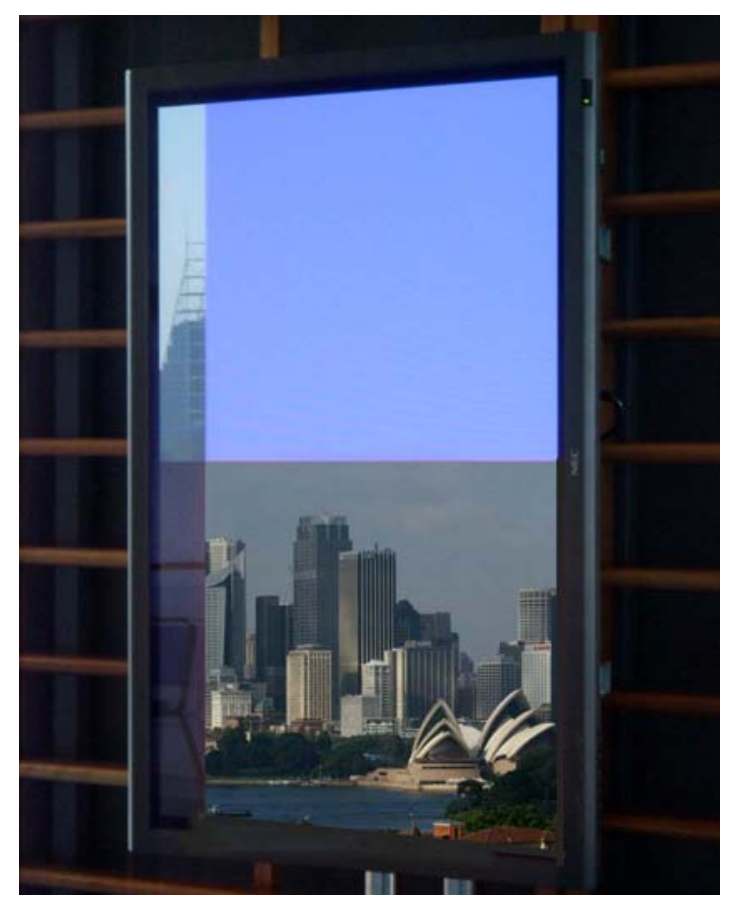

Figure 8 Cities Tango in Belfast: including a real-time image from the Sydney gallery (see online version for colours)

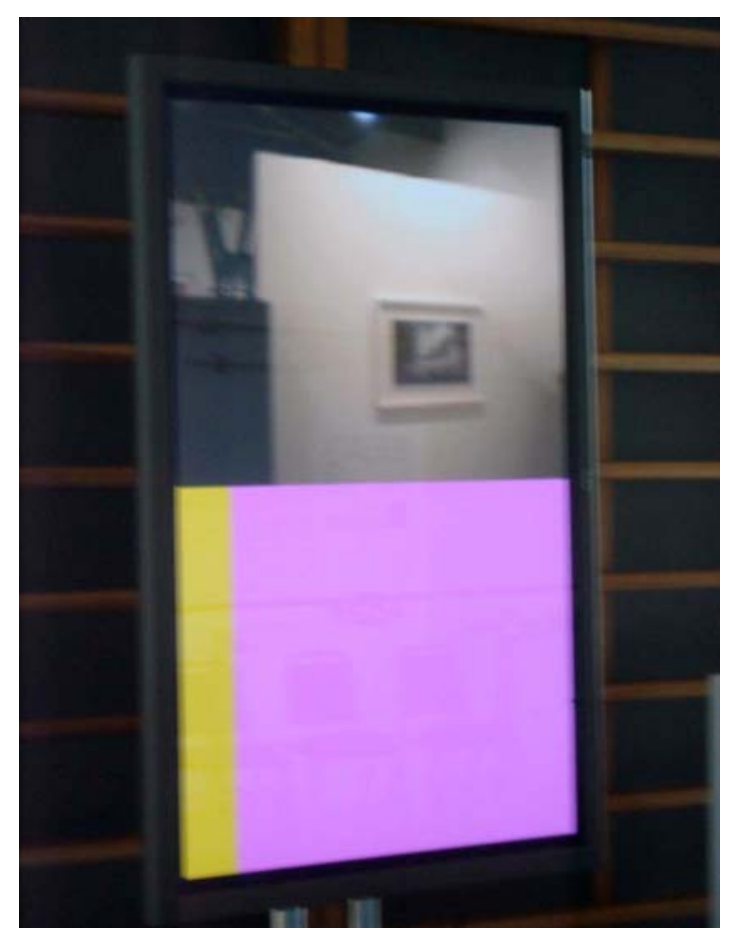


Figure 9 Tango Tangle in Federation Square (see online version for colours)

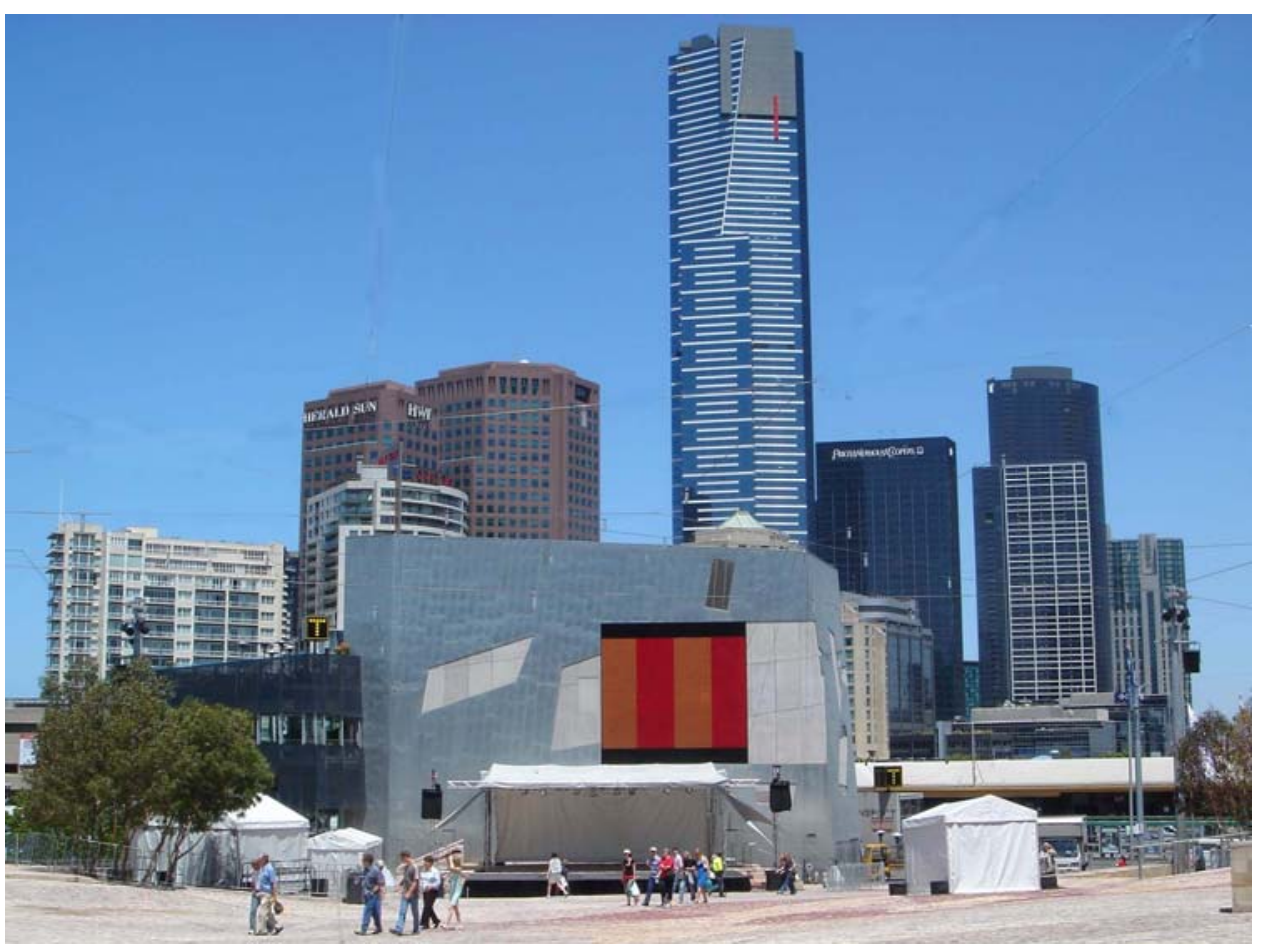

In the Cities Tango displays, images of and from the remote location are dynamically revealed within the otherwise abstract structure. A set of identical shots, taken at different times of day, are interlaced with the colour stripes and shown in the 'other' city. The images are, in effect, treated as abstract objects within the work. The colours used, the times of day selected and the pace of the work are influenced in each location by a combination of the detected audience behaviour at both locations.

The two cities, Belfast and Sydney, interact with one another across continents and time zones. In particular, the colours, stripes and timings used are driven by movements at the remote location, so that in the European day Belfast may see 'night' colours, for example, and Sydney may see 'day' ones. On the other hand, the display, from time to time, of real time images from the remote location is influenced by the local audience. Immediate responses to movement are seen by the 'audience' in their own location. The live connection is sensed through the real time images. It created a small stir, for example, when people in the Sydney gallery recognised Ernest Edmonds appearing on their display. He was, of-course, in Belfast.

\section{Conclusions}

The notion of communication that informed the early work discussed above was one of meaningful interaction in the sense of, for example, the ways that TGR Bower found that new born infants explored the world around them. They took actions, observed what happened and, in a very real sense, seemed to form theories that could be tested. They 
began learning how to communicate through the exploration of actions purposefully taken. The Communication Games constructed provided highly constrained environments that placed the audience in a similar position within a new form of visual art.

Our appreciation of visual art depends on seeing it in context. The atmosphere, the light, the space, the audience are all part of the experience of a work. When we view an oil painting screened by plate glass, the glass is a component of the experience of the work. When we peer through to a work surrounded by a crowd, the audience becomes part of that experience too. In interactive art, the audience is deliberately made a component of the work: the person in the art space becomes an active participant.

In participative interaction, the artefact is just one element of the whole experiential space. But what exactly do we mean by interaction? The words influence, stimulus, interchange are more evocative and appropriate for my works. If we add a layer of meaning to the situation, we can say that the influence of the human system on the art system comes about as a result of stimulus, interchange or even cooperation and conversation. The artwork and the audience are interacting systems that influence one another (Edmonds, 2007). Generative art systems like Shaping Form are open to influence and develop over time as a consequence of that influence. This kind of computational generative art is an open system at the very heart of its design. The influences that occur in such open systems provide a mechanism for a form of communication that is entirely in sympathy with the ideas that inspired the early Communications Game art works.

In Cities Tango, the internet is employed to construct a two node communication game that links public places in remote cities. There is no relationship to a video conference concept here. As with the early work, the communication is not that easy to follow. It is not a direct imitation of face-to-face communication, but a form of communication nonetheless. A communication mediated through what is essentially an abstract distributed and active channel.

\section{Acknowledgements}

Some of this paper is partly drawn from a shorter one that was presented in a meeting in February 2010 (Edmonds and Franco, 2010) and the content was presented at the Computational Aesthetics Conference at the BCS, London, in 2010.

\section{References}

Ascott, R. (2003a) 'Telematic embrace', in Shanken, E.A. (Ed.): Visionary Theories of Art, Technology, and Consciousness, University of California Press, Berkeley, CA.

Ascott, R. (2003b) 'Navigating consciousness: art and transformative technologies', Planetary Collegium, February, Leonardo/Olats.

Bilda, Z., Edmonds, E. and Turnbull, D. (2007) 'Interactive experience in a public context', Proceedings of Creativity and Cognition, ACM Press, NY, pp.243-244.

Bower, T.G.R. (1974) 'Development of infant behaviour', Br. Med. Bull., Vol. 30, No. 2, pp.175-178.

Cornock, C. and Edmonds, E.A. (1973) 'The creative process where the artist is amplified or superseded by the computer', Leonardo, Vol. 6, No. 1, pp.11-16. 
Cornock, S. (1971) Art and Cognition, Leicester Polytechnic, Systems Research, Leicester, England.

Edmonds, E.A. (1971) 'Communications game', Control Magazine No. 6, p.14.

Edmonds, E.A. (1975) 'Art systems for interactions between members of a small group of people', Leonardo, Summer, Vol. 8, No. 3, pp.225-227.

Edmonds, E.A. (1990) 'Video construct communication systems', Control Magazine, p.14.

Edmonds, E.A. (2007) 'Reflections on the nature of interaction', CoDesign: International Journal of Co-Creation in Design and the Arts, Vol. 3, No. 3, pp.139-143.

Edmonds, E.A. (2009a) 'Constructive computation', in Brown, P., Gere, C., Lambert, N. and Mason, C. (Eds.): White Heat Cold Logic, pp.345-360, MIT Press, Cambridge, Massachusetts.

Edmonds, E.A. (2009b) 'Cities Tango: between Belfast and Sydney', in Mey, K.E.A. (Ed.): Interface, ISEA2009, University of Ulster, Belfast, Ireland.

Edmonds, E.A. and Amitani, S. (2008) 'Shaping forms on the web with a collective memory', 7th International Conference on Software Methodologies, Tools and Techniques: SoMeT'08, American University of Sharjah, UAE, 15-17 October.

Edmonds, E.A. and Franco, F. (2010) 'Art of conversation', CAT 2010: Ideas Before Their Time: Connecting the Past and Present in Computer Art [online] http://www.bcs.org/server.php?show=conWebDoc.34179 (accessed 12 February 2010).

Groupe de Recherche d'Art Visuel (GRAV) (1963) Proposition Pour un Lieu d'Activation, Paris.

Jennings, P. (Ed.) (2007) Catalogue: Speculative Data and the Creative Imaginary, National Academy of Sciences Gallery, Washington, DC, USA.

Mallen, G. (2009) 'Bridging computing in the arts and software development', in Brown, P., Gere, C., Lambert, N. and Mason, C. (Eds.): White Heat Cold Logic, pp.194-198, MIT Press, Cambridge, Massachusetts.

Manzo, A.J. (2011) Max/MSP/Jitter for Music, Oxford University Press, Oxford, UK.

Mason, C. (2008) A Computer in the Art Room - The Origins of British Computer Arts 1950-80, pp.118-120, JJG Publishing, Norfolk.

Popper, F. (Ed.) (1968a) Electra - Electricity and Electronics in the Art of the 20th Century, Musée d'Art Moderne, Paris.

Popper, F. (1968b) Origins and Developments of Kinetic Art, Studio Vista, London, Paris.

Swade, D.D. (2008) 'Two cultures: computer art and the science museum', in Brown, P., Gere, C., Lambert, N. and Mason, C. (Eds.): White Heat Cold Logic, pp.203-218, MIT Press, Cambridge, Massachusetts.

Willats, S. (1968) Exhibition Catalogue, Visual Automatics and Visual Transmitters, Museum of Modern Art, Oxford. 